\title{
Reflexões sobre possibilidades metodológicas da Teoria Ator-Rede
}

\section{Reflections about methodological possibilities of the Actor-network Theory}

Júlio Cesar de Almeida Nobre ${ }^{1}$

Artigo

Rosa Maria Leite Ribeiro Pedro ${ }^{2}$

Original

Original

Paper

Palavras-chave:

Redes

Controvérsia

Cartografia

Mediação.

\section{Resumo}

O presente artigo busca realizar uma reflexão acerca das possibilidades metodológicas da Teoria Ator-Rede (TAR) para a abordagem do social. Nesse sentido, busca-se, inicialmente, caracterizar essa teoria, cujos conceitos procuram dar conta de uma realidade que vai sendo produzida, apontando para um processo de constante redefinição. Em seguida, defende-se a controvérsia como um observatório diferenciado para o rastreamento do fluxo dessas redes. Por fim, considera-se a importância de um método cartográfico que possibilite uma ampliação da presença de diferentes mediadores, que participam da descrição das redes; descrição esta que, nessa perspectiva, reveste-se de expressiva relevância metodológica na produção dos relatos.

\section{Abstract}

The present article aims to accomplish a reflection concerning Actornetwork Theory (ANT) methodological possibilities for approaching the social. In that sense, we first characterize this theory, as well as its concepts that try to account for a reality that is constantly produced, pointing to a process of permanent redefinition. Then, we point out the controversies as a differentiated laboratory to follow the flow of these nets. Finally, we consider the importance of the cartographic method in the way it makes possible an enlargement of the presence of different mediators, that take part in the description of the networks; the description assumes, then, an expressive methodological importance in the production of the reports.
Key words:

Networks

Controversy

Cartography

Mediation 


\section{Introdução}

A teoria Ator-Rede- desenvolvida por Bruno Latour, John Law entre outros pesquisadores- apresenta um olhar voltado para as práticas cotidianas a envolver ciência, tecnologia e sociedade. Temos amarrações de humanos e não-humanos - que, por sua vez, são também mais amarrações - configurando, portanto, um emaranhado de redes que fragmentam qualquer solidez em microconexões ou desconexões. Tal emaranhado nos possibilita pensar não mais em termos de unidade, mas a partir de um dinamismo processual e sempre constante de associações.

Diferentemente de uma perspectiva sociológica mais tradicional, Latour (2008) não busca uma visão focada apenas nos interesses que envolvem um fato para explicá-lo - o que configuraria uma realidade explicada a partir de seu "contexto". Para ele, a disputa de interesses é insuficiente para compreender a produção dos fatos e não deve ser tomada como um fator determinante nesta produção. $\mathrm{O}$ sociólogo das ciências aponta que os não-humanos - os artefatos tecnológicos - têm importante participação na construção de toda e qualquer solidez. No referencial das redes existe uma simetria no tratamento do social e do tecnocientífico. A análise das redes, portanto, deve adquirir uma perspectiva sociotécnica, seguindo os processos conectivos sociedade afora (TEIXEIRA, 2001). A circulação nas tramas da rede se dá por meio de hibridações/ traduções e, neste processo de deslocamentos diversos, uma realidade vai sendo produzida. A constante busca por uma pureza - a decantação entre natureza e sociedade - acaba por renovar, criar novos problemas que apontam para uma existência sempre bifurcada e uma instabilização da realidade social e natural. Purificar é, portanto, igualmente misturar/hibridar. É traduzir. As purificações deslocam os ordenamentos em processos não lineares e os híbridos entram em cena como potência de criação e imprevisibilidade, inerente aos agenciamentos diversos proporcionados pelas próprias purificações.

Apostando na fertilidade da teoria AtorRede, o presente artigo tem por objetivo realizar uma reflexão acerca das possibilidades metodológicas de tal proposta teórica.
Diferentemente de uma perspectiva que acaba por sedimentar um rígido contexto social utilizado para explicar a realidade, buscamos conferir potência aos mediadores e seus agenciamentos produtores de existências.

\section{A Perspectiva das Redes}

$\mathrm{Na}$ concepção de redes, as mediações ganham destaque e apontam para um processo de constante redefinição. Não há nenhuma garantia de uma estabilidade pré-determinada , a priori, por um centro normatizador que esteja fora do campo imanente de tais processos de agenciamentos e nenhuma transcendência normatizadora fora do tempo. Todo mediador é entendido, aqui, como seres/agenciamentos que não são nem puros humanos e nem puros não-humanos. Latour os denomina actantes. Nas próprias palavras do sociólogo:

O segredo é definir o ator com base naquilo que ele faz - seus desempenhos (...). Uma vez que, em inglês, a palavra actor (ator) se limita a humanos, utilizamos muitas vezes actant (atuante), termo tomado à semiótica, para incluir não-humanos na definição (LATOUR, 2001: 346).

Tais mediações geram redefinições da realidade, tecendo novas geografias e novos controles. Novas coerções exercem pressão sobre velhas coerções e as deslocam, descentram. A produção em rede aponta para o transbordamento de tais campos que delineia novos ordenamentos na justa proporção de seus movimentos. A produção de um coletivo vai se dando por intermédio desses fluxos que se reapropriam da existência na construção do novo. Segundo John Law (1987), toda rede é

(...) um processo de "engenharia heterogênea", no qual elementos do social, do técnico, do conceitual e do textual são acoplados e, então, convertidos (ou "traduzidos") em um conjunto de produtos científicos igualmente também heterogêneo. Isto acontece na ciência. Mas eu também já afirmei que a ciência não é muito especial. Logo, o que é verdadeiro para a ciência, também pode sê-lo para outras instituições. Assim, 
a família, a organização, os sistemas computacionais, a economia e as tecnologias - toda a vida social - podem ser delineadas de modo similar. Todos são redes organizadas de materiais heterogêneos cuja resistência foi superada. Este é o movimento crucial feito pelos autores da teoria ator-rede: a sugestão de que o social não é nada mais do que redes de materiais heterogêneos (LAW, 1992: 2).

Annemarie Mol (2007) parece estar em grande sintonia com Latour e Law quando desenvolve sua concepção de uma Política Ontológica. O termo política pontua um caráter sempre ativo e indeterminado no processo de modelação das ontologias. Evidencia-se aqui, o termo ontologias no plural. O objetivo é apontar para uma realidade sempre múltipla, que não é dada anteriormente às práticas cotidianas. Annemarie Mol, porém, diferencia claramente o conceito de múltiplo do conceito de plural, este último intimamente associado às concepções de perspectivismo e construtivismo. No perspectivismo, concebe-se um real único diante de diferentes perspectivas. Podemos considerar aqui, uma primeira versão do pluralismo. Outra versão pode ser encontrada no construtivismo, por meio de histórias que desenrolam o nascimento de um fato. Tais histórias deixam evidente como qualquer fato nunca está dado a priori e, ainda, que outras possibilidades sempre acabam por deixar de se fazer presentes no decorrer do tempo. Essa abordagem indica que existem diversas e plurais possibilidades no passado. Temos aqui mais uma versão do pluralismo - que aponta para os vencidos da história.

Quando Mol desenvolve o conceito de múltiplo, busca conceitos que saiam do pluralismo simples, o que implica afirmar a possibilidade de diferenças que não se comunicam e colocar ênfase nas conexões. Assim como em Latour, o foco está na cozinha dos fatos, nas mediações, nas práticas. Annemarie encontra tal possibilidade no conceito de performance.

[As performances] sugerem uma realidade que é feita e performada [enacted], e não observada. Em lugar de ser vista por uma diversidade de olhos (...) a realidade é manipulada por meio de vários instrumentos, no curso de uma série de diferentes práticas. Aqui é cortada a bisturi; ali está a ser bombardeada por ultrasons; acolá será colocada numa balança e pesada. Mas enquanto parte de actividades tão diferentes, o objeto em causa varia de um estádio para o outro (MOL, 2007: 6).

Instrumentos e práticas acabam por performar as existências dos objetos - de diferentes objetos. As técnicas aqui não são neutras, são actantes de uma realidade sempre múltipla. Estamos, portanto, diante de uma multiplicidade de performances, traduções da existência. Sempre que nos deparamos com uma realidade aceita como "natural", podemos rastreá-la como uma produção, um efeito de uma cadeia de transformações, de processos de hibridação. Existem etapas em que se subtraem elementos e acrescentam-se outros e cada elo segue sempre materializado em um mediador. De elo em elo, a realidade é construída em camadas. Trata-se de um processo de endurecimento da vida em certezas, as quais dependem de todas essas amarrações. Vejamos tais processos apoiados nos estudos de Latour (2000), que afirma que um fato pode ser entendido a partir do conceito de caixa preta, que em teoria de sistemas é suposta quando um componente é considerado por demais complexo.

Abordar tal complexidade como uma caixa-preta equivale afirmar que toda e qualquer discussão sobre seu conteúdo - da caixapreta - se encerra e faz-se necessário apenas o conhecimento de suas entradas e saídas. Uma caixa-preta começa a ser formada, isto é, um enunciado começará a ganhar a solidez de um fato sempre que for introduzido em novas formulações na condição de premissa inquestionável. Sempre que uma produção é exportada e "comprada" dessa forma - sem maiores controvérsias - por outros, ela se solidifica um pouco mais. A cada nova "compra", maior a solidez. Qualquer fato deixa sempre um rastro de "compras", onde segue cada vez mais implícito em todos os novos aliados que o "compraram". Sendo assim, pode-se perceber que a solidez de um fato depende sempre de todos aqueles que o mantêm em movimento - tanto humanos como não-humanos - e formam uma legião de aliados interligados. Vemos um verdadeiro exército alinhado para a batalha.

Porém, sempre que um fato encontrar alguma oposição, algum obstáculo em sua cir- 
culação, será empurrado para a "falsidade". A tentativa, aqui, é de que alguns aliados traiam seus porta-vozes. Muitas vezes encontraremos, nesse momento, um ambiente de controvérsias. Entraremos em uma batalha dos fatos, que possibilita a "abertura" de uma caixa-preta. Latour faz uma diferenciação entre modalidades positivas - são sentenças que afastam o artefato de sua condição de produção - e modalidades negativas - argumentos que conduzem o artefato para sua condição de produzido. Tais modalidades não se situam apenas no campo da política, mas no campo do tecnológico também. São processos de tradução.

Outra possibilidade de controvérsias está no que Latour (in PEDRO, 2005) chama de caixa-cinza. Caixa-cinza seria a condição de um artefato que ainda não conseguiu se estabilizar. Se caixa-preta designa o fim das discussões e ausência de controvérsia, é na caixa cinza que estas retornam com toda a força.

Em meio a tais controvérsias, podemos ver aquilo que Latour denomina como formação de grupos e antigrupos. Tal conceito indica que o surgimento e desenvolvimento de uma controvérsia se dão simultaneamente à produção de grupos fortemente dispostos em oposição. Desse modo, deparamo-nos com argumentos bastante fortes a favor das fronteiras grupais. A fronteira dos grupos é sempre mantida ao se delinear os outros vínculos de agrupamentos como negativizados. É na comparação com os demais vínculos que se atenta para os próprios, formando, assim, os grupos e antigrupos, os de dentro e os de fora. E, conforme pudemos observar, os próprios atores acabam construindo um mapa de análise das relações estabelecidas. Muitos são os aliados trazidos pra a defesa dos limites grupais. Ciência, filosofia, religiões, leis, tecnologias, etc. A existência de um grupo depende sempre de um constante trabalho. Consequentemente, entendemos que um ponto interessante do estudo das redes reside exatamente nas controvérsias acerca dos diferentes sentidos de pertencimentos/traduções, formados.

Quanto maior a discordância, mais "profunda" - e cara - ficará tal controvérsia, visto que muitos serão os actantes que precisarão ser trazidos à cena para que sirvam de aliados para os argumentos utilizados. Estes passarão a ser sustentados por muitos. A solidez nada mais é que um efeito de um alinhamento de aliados, articulados na defesa de um argumento. A controvérsia ressurge sempre que essas ligações são postas à contraprova. Para tal tarefa, o postulante terá que se embrenhar em um mundo de caixas-pretas interconectadas, uma rede que mistura papéis, dinheiro, pessoas, universidades, máquinas, enfim, humanos e não-humanos, fazendo com que os aliados mudem de lado e traiam o argumento que se apresenta como fato.

Quem está certo? Em quem deve o leitor acreditar? A resposta a essa pergunta não está em nenhuma das afirmações, mas naquilo que todos irão fazer com elas daí por diante. (...) o destino das coisas que dizemos e fazemos está nas mãos de quem as usar depois (...). Atentando apenas para eles, para suas propriedades internas, ninguém consegue decidir se são verdadeiros ou falsos, eficientes ou ineficientes (...). Essas características só são adquiridas pela incorporação em outras afirmações, outros processos e outras máquinas (LATOUR, 2000: 51-52).

Quando um fato se torna uma caixapreta, significa que este criou uma autonomia, uma independência. Porém, quanto mais independente este parece ser, mais humanos e nãohumanos trabalham para mantê-lo. John Law aborda a aparente autonomia de um artefato utilizando-se do termo pontualização.

(...) se uma rede age como um bloco único, ela desaparece e é substituída pela própria ação e pelo aparentemente simples autor desta ação. Ao mesmo tempo, é apagada a maneira pela qual o efeito é gerado: ele deixa de ser visível ou relevante. É desse modo que algo muito simples - uma televisão que funciona, um banco bem gerenciado ou um corpo saudável - acabam mascarando, por um tempo, as redes que o produzem (LAW, 1992: 5).

Tentativas de pontualizações sempre precárias e ameaçadas pela falha se dão. Porém,

(...) recursos pontualizados propiciam um modo de desenhar rapidamente as redes do social sem ter que lidar com uma complexidade infinita. E a medida 
que são incorporadas nesses esforços de ordenamento, são performadas, reproduzidas e se ramificam através das redes do social (LAW, 1992: 5).

Observamos muita luta. Invariável tensão. Nadaé totalmenteíntegro, inteiro. Pontualizações são também processos, produções - um trabalho sempre presente no sentido de tentar uma vitória sobre as resistências. Portanto,

(...) a análise da batalha pelo ordenamento é central à teoria ator-rede. O objetivo é explorar e descrever os processos locais de ordenação social, ordenamento e resistência. Em resumo, explorar o processo que é frequentemente chamado de translação, que gera efeitos de ordenamento, tais como dispositivos, agentes, instituições ou organizações (LAW, 1992: 5).

Situando-nos permeados por tais embates, podemos vislumbrar os processos de abertura e fechamento de caixas-pretas e a formação de solidez em meio às redes. Desse modo, diferentemente de um entendimento do social como um estado estável de coisas, um sólido fator que interconecta humanos, um denso contexto a que costumamos nos reportar sempre que desejamos explicar certos aspectos da realidade, a Teoria Ator-Rede entende que um social enrijecido não pode dar conta de instabilidades. Em momentos de fortes controvérsias, por exemplo,

(...) em que são incertas as fronteiras dos grupos, nas que flutuam a variedade de entidades a considerar, a sociologia do social já não é capaz de rastrear as novas associações dos atores (...): já não é suficiente limitar os atores ao rol de informantes que oferecem casos de alguns tipos muito conhecidos. Há que restituir-lhes a capacidade de criar suas próprias teorias do que compõe o social (LATOUR, 2008: 27).

A direção aqui é dada pelos próprios actantes. A ordem é trazida pelo próprio desdobramento das controvérsias em que estes estão imbricados. Faz-se necessário rastrear as suas articulações controvertidas sem procurar imporlhes um sentido a priori. A busca de padrões.
(...) É comparável ao que faz um cartógrafo ao tratar de registrar a forma de uma costa estranha em um pedaço de papel. (...) Do mesmo modo, a TAR sustenta que é possível rastrear relações mais robustas e descobrir padrões mais reveladores ao encontrar a maneira de registrar os vínculos entre marcos de referência instáveis e mutantes em vez de tratar de manter estável um marco (LATOUR, 2008: 43).

Deixam-se as diversas categorias sociológicas, psicológicas, etc, de lado e dá-se voz aos mediadores. Muitas são as incertezas com que se tem que debruçar no processo de construção de uma existência sempre bastante instável. Nas redes, os mediadores não transportam, simplesmente, as forças sociais ou materiais. O que temos são circuitos de agenciamentos. Estes exercem coerções, fazendo com que os associados sejam transformados, “(...) de tal modo que façam os outros fazerem coisas” (LATOUR, 2008: 156).

A partir desse referencial, não existe um sólido macro - social - a explicar um mundo micro. Temos sim, um circuito de mediadores que, de tradução em tradução, tece a realidade. A análise das redes precisa, sim, tentar descrever tais mediações.

Annemarie Mol aponta, igualmente, para todas essas conexões quando afirma que

(...) os objetos performados não vêm sozinhos: trazem consigo modos e modulações de outros objectos. (...) Com a anemia laboratorial, vem a agulha, a extracção de sangue do corpo, a aplicação involuntária de dor. E assim sucessivamente (MOL, 2007: 13).

A pesquisadora salienta, aqui, a importância daquilo que ela chama de fenômeno da interferência. Estas são modulações complexas, articulações diversas que performam a realidade dos fatos. A avaliação das performances, portanto,

Com efeito, (...) nunca chegará a nenhum termo estável, porque há elementos a mais. Tal implica que é pouco provável que a política ontológica estabilize, uma vez concluídas as descrições que dela sejam feitas - porque jamais serão concluídas. Tolerar fins 
em aberto, enfrentar dilemas trágicos e viver sob tensão, é mais isto que se passa (MOL, 2007: 16).

É importante notar que toda essa atividade não emana de um centro único, capaz de gerenciá-la, o que não significa dizer que não há poder. Há sim um poder difuso, espalhado pela rede, às vezes distribuído, outras vezes cristalizado em alguns nós. Os ordenamentos que a partir daí se produzem serão mais ou menos estáveis, mas nunca totalmente fixos. Trata-se de uma produção de ordenamentos a partir de mediações. Os movimentos que a partir daí se produzem desenham novos espaços.

(...) o que a multiplicidade implica é que embora as realidades possam ocasionalmente colidir umas com as outras, noutras alturas as várias performances de um objecto podem colaborar e mesmo depender umas das outras (MOL, 2007: 16).

Assim, se as redes são, por um lado, coerção, por outro são possibilidades, abertura. A abertura se encontra, precisamente, nos escapes da coerção, nos escapes dos lugares, nessa espécie de quase-lugar das mediações. Os conceitos de recalcitrância e de plasma desenvolvidos por Latour se fazem bastante importantes nesse ponto.

A recalcitrância do objeto será uma questão de não domínio, enquanto desconsideração, por parte do actante quanto às teorias que pretendem encaixá-lo num referencial interpretativo estável (ARENDT, 2008: 7).

Se a recalcitrância revela certa resistência às estabilizações, o plasma aponta para aquilo que não está sequer conectado às redes e que segue invisível, desconectado. O plasma não tem ainda uma forma. Escapa por entre as malhas das conexões até então estabelecidas. É aquilo que ainda não é conhecido, mas que está presente como virtualidade. Não é um fora do mundo, mas uma presença muda. Tais aberturas, escapes, parecem estar bastante evidenciadas em momentos de controvérsias. Estas parecem gerar vertigens em espaços cristalizados Propomos, para lidar com tais escapes, misturas, instrumentalizar a noção de redes ou coletivos.

\section{Construindo um Método - Uma Cartografia de Redes de Controvérsias}

Conforme já abordamos anteriormente, a condição de algo que ainda não se estabilizou como caixa-preta é chamada, pelos sociólogos das ciências e das técnicas, de caixa-cinza. Ao nos valermos da condição de caixas-cinza de certos artefatos, podemos apreender um coletivo de mediações, negociações de interesses que mantêm articulados humanos e nãohumanos. Como ressalta Pedro (2008), esse corpo conceitual requer uma metodologia de trabalho que possa lhe fazer ressonância, capaz de cartografar tais redes em termos de sua geografia - principais actantes, porta-vozes e respectivas conexões - e de sua dinâmica fluxos das diferentes traduções:

\begin{abstract}
Nesse sentido, cartografias são sempre provisórias, funcionais até o momento em que novas cartografias - portanto, novas paisagens - se imponham. $\mathrm{O}$ ofício do cartógrafo envolve, assim, uma implicação nas redes que ele cartografa, um entendimento sem exterioridade de seus movimentos e desvios. Para tanto, lhe é conveniente um equipamento bastante "minimalista" (...) sempre aberto a redefinições (PEDRO, 2008: 11-12).
\end{abstract}

Bruno Latour (2000) considera algumas regras como necessárias para uma abordagem das redes, cuja negligência acarretaria uma perda de caminho em relação ao acompanhamento de redes ou coletivos. Seriam sete, as regras metodológicas a serem seguidas:

1. Devemos objetivar um fato sempre em ação - e nunca cristalizado -, situando-nos em momentos de construção de caixas-pretas, isto é, momentos em que o tema em questão ainda é objeto de controvérsias.

2. A condição de artificialidade ou de natureza de um fato é efeito dos processos de circulação nas redes.

3. A estabilização da natureza é sempre consequência de resolução de controvérsias - e não a sua causa.

4. A estabilidade da sociedade é sempre, também, consequência da resolução de controvérsias. 
5. Devemos nos colocar em simetria no que tange ao estabelecimento de qualquer polaridade e observar todos os nós que estão sendo amarrados nesses processos.

6. Precisamos atentar para a extensão da rede que é construída em toda situação de controvérsias que envolvam acusação de irracionalidade e busca de explicações sociais ou lógicas que justifiquem tal acusação.

7. Faz-se necessário o rastreamento da rede que sustenta qualquer qualidade especial a qual atribuímos uma dose de estabilidade.

Podemos perceber, nesses passos sugeridos por Latour, que um observatório de diferenciada importância para o rastreamento de redes está, exatamente, nas controvérsias. É apenas no processo da produção de novas associações que o social se faz visível. A visibilidade é sempre momentânea. Após as conexões terem sido feitas, apesar de continuar havendo bastante trabalho para fazê-las existir, tal trabalho acaba por ficar invisível nos processos de fechamento das caixas-pretas. Os mediadores seguem agora como sendo simples intermediários. Desse modo, para analisar um social, é preciso existir alguma prática de pesquisa que traga visibilidade a eles - que faça com que objetos mudos possam falar.

Segundo Latour (2000, 2001, 2008), uma solução para tal problema - e que focalizaremos no presente trabalho - seria estudar os processos de inovações, a cozinha dos fatos, pois é nesses ambientes que os objetos ganham maior visibilidade. Nesses momentos, as conexões ficam bastante expostas por meio de controvertidas tramas.

No geral, a grande vantagem de visitar uma obra em construção é que oferece um ponto de vista ideal para observar as relações entre humanos e não-humanos. Uma vez que os visitantes têm os pés bem metidos no barro, sentem rapidamente o espetáculo de todos os participantes trabalhando duro no momento (LATOUR, 2008: 131).

A perspectiva das redes demanda uma metodologia que nos possibilite trabalhar entre a solidez dos fatos endurecidos e os fluxos na dinâmica de construção e desconstrução de caixas-pretas. Isso requer que nos coloquemos em simetria no que tange ao estabelecimento de qualquer polaridade, discernindo o que está sendo mobilizado em cada argumento. No acompanhamento das controvérsias, precisamos atentar para a extensão da rede que é construída, ou seja, perceber que os actantes são sempre pontualizações de redes bem mais vastas e heterogêneas. Desse modo, pensamos que a análise das controvérsias pode nos ser uma ferramenta de singular importância para mapear as redes que articulam humanos e não-humanos.

A análise das controvérsias ganhou destaque no período de 1970, quando ocorreu um crescimento das pesquisas sociológicas que procuravam entender os fundamentos do comportamento da comunidade científica e da formação e evolução das ideias dessa comunidade. Foi a partir de pesquisas feitas por Nelkin e Mazur (in VELHO \& VELHO, 2002) que se começou a desenvolver, com maior intensidade e profundidade, os estudos de controvérsias. Tais autores se permitiram focalizar e entender a maneira pelo qual o poder do conhecimento científico dependia de negociações e debates entre as partes interessadas, envolvendo diferentes segmentos da sociedade - o que já nos dá uma pista de que acompanhar as controvérsias é, igualmente, apreender a mistura entre conhecimento e sociedade.

O termo controvérsia refere-se a uma disputa em que se alegam razões pró ou contra, onde se podem evidenciar movimentos cujo desdobramento será a consecução de um objetivo comum. Para se originarem tais controvérsias, necessita-se que exista algum tipo de produto ou processo - foco da disputa e que existam porta-vozes de modalidades negativas e positivas respectivamente, isto é, construam argumentações que conduzam ou afastem os artefatos para/de uma condição de produzidos. A partir da análise de tais embates, alguns autores sugerem que uma das principais revelações dos estudos de controvérsias é o uso que as partes oponentes fazem de informações e conhecimentos conflitantes. O que se busca evidenciar, com isso, é que não há "fatos puros" e tampouco a informação é algo neutro; em outras palavras, que os argumentos mobilizados implicam jogos de poder e força que se expressa na solidez que os fatos vão adquirindo. De acordo com Pedro (2005), compreender e mapear as controvérsias requer uma especial atenção aos dispositivos de saber-poder que 
estão em ação nas redes, lembrando que os argumentos lançados não são apenas técnicos, mas estão fortemente entrelaçados com crenças, interesses e com as outras redes em que os cientistas estão inseridos. Logo, o passo inicial no sentido do entendimento das controvérsias é o de compreender as forças que geram essas pontualizações e conhecimentos em conflito. Como nos diria Bruno Latour (2000), precisamos nos manter simétricos e não assumir nenhuma polaridade.

A análise de controvérsias, portanto, parece sintonizada com o pressuposto de que procedimentos experimentais e regras objetivas não são suficientes para resolver disputas sobre fatos; vemos uma imbricação de humanos e não-humanos a construir a existência. Em sintonia com o referencial das redes, sempre que ocorre a resolução de uma controvérsia ou disputa nessa área, tal resolução é alcançada a partir de pressões, acordos que não incluem apenas os conhecimentos aceitos, mas também os interesses e objetivos dos humanos, bem como a mobilização de não humanos que lhes servem de "aliados". Conhecimentos e humanidades, natureza e sociedade se misturam em meio à controvérsia e sua possível resolução. Uma engenharia bastante heterogênea é produzida.

Assim como um detetive que rastreia as ruelas enigmáticas do seu caso investigativo, nós devemos seguir as pistas que aparecem a cada momento, os mediadores que nos convocam a desviar, construir caminhos, costurar circuitos. Uma frase ecoa nesse momento: “(...) registrar, não filtrar; descrever, não disciplinar" (LATOUR, 2008: 86). Desse modo, devemos buscar seguir tais indícios, aplainando um terreno ruidoso, por meio de uma cartografia, focalizando nos mediadores; nenhuma explicação que reporte a uma dimensão de profundidade, apenas o terreno sinuoso dos deslocamentos e seu mapeamento. As controvérsias são de importância crucial para a realização de tal intento. Estas trazem a possibilidade da visibilidade de processos - caixascinza - que, em outros momentos, são bastante opacos - como caixas-pretas. Acreditamos que a abordagem das controvérsias nos traz a possibilidade de rastrearmos as fluidas conexões que constroem a existência. Trata-se de um trabalho de descrição, cuja principal característica, segundo Latour, é que se deve avançar lentamente. Uma descrição não é algo simples, pois

Descrever, estar atento ao estado de coisas concreto, encontrar a única forma adequada de descrever uma situação dada, para mim isso é sempre incrivelmente difícil (LATOUR, 2008: 209).

O objetivo seria uma descrição mais plana, sem apelar para uma "profundidade" que agregue volume à realidade. Não queremos, portanto, produzir uma dimensão ainda mais profunda que as anteriormente construídas. Nosso foco é outro. A descrição, a partir dos rastros deixados pelos mediadores, acaba por apontar para um processo de produção da existência. Uma análise de tais processos deve avançar lentamente de tradução em tradução, e objetivar a produção daquilo que Latour denomina como um relato. É importante salientar que esse relato nada mais é que outro mediador. Um texto nunca é um intermediário de uma sólida verdade, mas sempre será artificial de ponta a ponta.

O foco, aqui, é apenas seguir os actantes e descrever. Apoiada em Bruno Latour, Pedro aponta que o processo descritivo deve, minimamente:

1) Buscar uma porta de entrada - É preciso encontrar uma forma de "entrar na rede (...) e, de algum modo, participar de sua dinâmica. 2) Identificar os portavozes - (...) é preciso identificar aqueles que "falam pela rede", e que acabam por sintetizar a expressão de outros actantes (...), não se pode deixar de tentar buscar as 'vozes discordantes' (...). 3) Acessar os dispositivos de inscrição, ou seja, tudo o que possibilite uma exposição visual (...) e que possibilitam 'objetivar a rede'; 4) Mapear as ligações da rede Trata-se aqui de delinear as relações que se estabelecem entre os diversos atores e nós que compõem a rede. Envolve as múltiplas traduções produzidas pelos atores, ressaltando-se suas articulações, em especial: os efeitos de sinergia ou de cooperação na rede; os efeitos de encadeamento ou de repercussão da rede; as cristalizações ou limitações da rede (PEDRO, 2008: 12). 
Segundo Castro (2008), tal método permite que identifiquemos os distintos portavozes envolvidos na controvertida trama e que possamos deixá-los falar. O pesquisador, no caso, é mais um dos porta-vozes que fala por muitos, coletando e mediando argumentos.

Quando o pesquisador se permite escolher os caminhos privilegiados para seguir os atores e o faz conscientemente, produz-se assim uma cartografia que diz respeito a uma situação específica, a um momento específico, segundo determinado pesquisador (CASTRO, 2008: 61).

Tais relatos devem ser entendidos como relevantes para a produção de conhecimento, possibilitando novas performances e novas produções de existência.

\section{Considerações Finais}

A partir da concepção de uma cartografia, entendemos que um texto acadêmico precisa funcionar como um laboratório, em que diferentes actantes possam falar. Flertar com a incerteza, atentando para os processos de mediação. O objetivo seria traduzir o social por intermédio de novos dispositivos - nesse caso, os textuais.

Se o social é um rastro, então o social pode ser re-rastreado; se é um articulação, pode ser re-articulado (...): um bom informe da TAR é uma narrativa ou uma descrição ou uma proposta onde os atores fazem algo e não se limitam a cair sentados. Em vez de somente transportar efeitos sem transformá-los, cada um dos pontos no texto pode converter-se em uma bifurcação (LATOUR, 2008: 186-187).

Desse modo, a objetividade de um texto é garantida com a "vida" que ele traz a cada passo, buscando manter o indeterminado das conexões sempre presente. Redes não são sólidas. Não se deve abordar um coletivo como uma estrutura dura e a representar no papel. Faz-se necessário seguir seus movimentos indeterminados e "colar" nele nossos instrumentos textuais. Desse modo, conforme aborda Latour, busca-se criar uma continuidade articulada entre o evento estudado e a performance literária. Não se intenciona alcançar um relato fiel de uma realidade.
Se tivermos êxito, (...) um bom informe representará o social no preciso sentido de que alguns dos participantes na ação - através da controvertida agencia do autor - serão articulados de tal modo que possam ser reunidos (LATOUR, 2008: 200).

O foco deve residir sobre uma multidão de actantes, nas mediações que subvertem, transformam, buscando acompanhá-los em seu percurso. Contornos vão se delineando na justa medida de nossos próprios movimentos. Se estes são mediadores - e não simples intermediários da figuração - cada amarração tem sempre o potencial para trair a figura produzida pelos atores. Temos indeterminação em todos os pontos.

A qualidade de concreto não resulta de preferir uma figuração antes de outras em lugar dos atores, senão do incremento, as explicações, da quantidade relativa dos mediadores acima da dos intermediários (LATOUR, 2008: 94).

Uma produção sempre processual. Uma intensa circulação, mediação que "faz fazer". Tais mediadores se encontram um ao lado do outro e não, como na lógica dos intermediários, um dentro do outro, delineado por um centro. O terreno é, assim, aplainado. Esse é o projeto político da Teoria Ator-Rede. Não procuramos usar um mesmo vocabulário já estabelecido para "ler" as novas mediações, pois estaríamos fazendo delas apenas um exemplo das forças já estabilizadas. Nesse sentido, a cartografia de um quadro controvertido que se procura traçar tem por foco permitir a emergência de argumentos diversos, dar voz a actantes múltiplos que se entrelaçam, se imbricam. 


\section{Referências Bibliográficas}

1. ARENDT, R. Considerações sobre os conceitos de recalcitrância e de plasma e sua relação com o conceito de não domínio na obra de Bruno Latour. In: VII Esocite - Jornadas Latino-Americanas de Estudos Sociais das Ciências e das Tecnologias, Rio de Janeiro, 2008.

2. CASTRO, R. B. Redes e Vigilância: Uma experiência de cartografia Psicossocial - estudo de caso no município de Guarujá, São Paulo / BR. Dissertação (Mestrado em Psicossociologia de Comunidades e Ecologia Social) Instituto de Psicologia, Universidade Federal do Rio de Janeiro, 2008.

3. LATOUR, B. Ciência em ação: como seguir cientistas e engenheiros sociedade afora. São Paulo: Editora UNESP, 2000.

4. A Esperança de Pandora. Bauru: EDUSC, 2001.

5. Reensamblar Lo Social: uma introdución a la teoria del actorred. Buenos Aires: Manantial, 2008.

6. LAW, J. Notes on the Theory of the Actor Network: Ordering, Strategy and Heterogeneity. Centre for Science Studies, Lancaster University, Lancaster LA1 4YN. 1992.

7. Disponível em: $<$ http://www.comp.lancs. ac.uk/sociology/papers/Law-Notes- onANT.pdf $>$ Acesso em 05 jan. 2006.

8. MOL, A. Política Ontológica. Algumas ideias e várias perguntas. In Nunes, J. A. \& Roque, R. (org.) Objectos impuros. Experiências em estudos sociais da ciência. Porto: Edições Afrontamento, 2007 - no prelo.

9. PEDRO, R. M. L. R. Tecnologias de vigilância: um estudo psicossocial a partir da análise de controvérsias. Anais do XXIX $^{\circ}$ Encontro anual da ANPOCS, CD-ROM, 2005.

10. Redes e Controvérsias: ferramentas para uma cartografia da dinâmica psicossocial. In: VII Esocite - Jornadas LatinoAmericanas de Estudos Sociais das Ciências e das Tecnologias, Rio de Janeiro, 2008.

11. TEIXEIRA, M. A ciência em ação: seguindo Bruno Latour. História, Ciências, Saúde-Manguinhos, Rio de Janeiro, v. 8, n. 1, 2001. Disponível em: $\quad<$ http://www.scielo.br/scielo. php?script $=$ sci_arttext\&pid $=$ S010459702 001000200012\&lng=pt\&nrm=iso $>$.

12. VELHO, L.; VELHO, P. A. controvérsia sobre o uso de alimentação alternativa no combate à subnutrição no Brasil. História, Ciências, Saúde - Manguinhos, vol. 9. (1). p. 125-157, 2002.
Endereço para Correspondência:

Júlio Cesar de Almeida Nobre

julio.nobre@foa.org.br

Rua Marcelo Monteiro Cesar, 140/402

São Geraldo - Volta Redonda - RJ

CEP: 27.253-600

Informações bibliográficas:

Conforme a NBR 6023:2002 da Associação Brasileira de Normas Técnicas (ABNT), este texto científico publicado em periódico eletrônico deve ser citado da seguinte forma: NOBRE, Júlio Cesar de Almeida; PEDRO, Rosa Maria Leite Ribeiro. Reflexões sobre possibilidades metodológicas da Teoria Ator-Rede. Cadernos UniFOA. Volta Redonda, Ano V, n. 14, dezembro 2010. Disponível em: <http://www.unifoa.edu.br/cadernos/edicao/14/47.pdf $>$ 